\title{
Use of phytocaps in remediation of closed landfills - correct selection of soil materials
}

\author{
I.R. Phillips, M. Greenway and S. Robertson
}

\begin{abstract}
Phytocapping is an emerging technology gaining interest as an alternate capping system in the management of closed landfills, particularly where leachate production occurs primarily through groundwater intrusion rather than surface infiltration. A field trial was undertaken at a former putrescible landfill to compare the performance of a phytocap and an engineered cap. The engineered cap comprised compacted subsoil, overlain by a gravel drainage layer, overlain by sandy clay loam topsoil. The phytocap comprised a layer of topsoil only. A range of native trees, shrubs and grasses were planted into each cap, and irrigated daily with landfill leachate of varying strength $(0,40$ or $100 \%)$. Laboratory and field-testing evaluated the effect of leachate on soil physical and chemical properties. Deterioration in the topsoil's hydraulic properties impaired leachate infiltration and encouraged surface erosion for both systems. Laboratory studies found that aggregate instability due to slumping was the major cause for the decline in soil hydraulic properties. The topsoil sorbed appreciable amounts of added ammonium, organic nitrogen and organic carbon, and transformed much of the added ammonium to nitrate within a 14-day period. Thus, the capping system has the potential to remove leachate contaminants if the hydraulic properties of the topsoil can be improved. The trial has shown the importance of correct testing prior to selecting soil materials for use in capping systems where infiltration of leachate and rainwater is encouraged rather than discouraged.
\end{abstract}

Key words: nitrogen, carbon, phytocap, phytoremediation, landfill leachate, capping systems

\section{INTRODUCTION}

Leachate management continues to be one of the major issues facing regulatory authorities responsible for the remediation of closed landfills. Various strategies for minimising leachate release into the environment can be engineered into landfill design such as drainage collection systems, cut-off walls, reactive permeable barriers, collection and recirculation systems, and the construction of low-permeability (engineered) surface

Received June 2004; revised and accepted August 2004

Authors

I.R. Phillips, M. Greenway, School of Environmental Engineering, Griffith University, Nathan, Qld, Australia, 4111

Email I.Phillips@griffith.edu.au

S. Robertson, City Design, Landfill Remediation, Brisbane City Council, Brisbane, Qld, Australia, 4006

LCR 655/2004 caps (Smith et al. 2003; Henken-Mellies and Gartung 2004). Engineered caps have been widely used as an effective method to minimise water entry into landfills, and consequently, the potential for leachate generation (Henken-Mellies and Gartung 2004). Consequently, engineered capping systems are recommended in environments where infiltration (rainfall, snow melt, etc.) exceeds evapotranspiration.

In sub-tropical environments such as that experienced in Brisbane, Australia, leachate generation through infiltration of rainwater is of much less importance than that generated through groundwater inflows. Of the 150 former landfills within the Brisbane area, most are in direct contact with groundwater, and $>80 \%$ of the leachate generated results from groundwater intrusion. Furthermore, Brisbane's rainfall is summerdominated and can occur from high-intensity storms, which encourage surface runoff rather than infiltration. Field research by Brisbane City Council (Thorley and Boczek 2001) indicated that infiltration in Brisbane's 
sub-tropical environment can be limited to less than $0.05 \%$ of precipitation without the use of multilayered caps, and even a $400 \mathrm{~mm}$ uncompacted subsoil layer reduced infiltration to $<2 \%$. The incorporation of fully engineered caps in landfill management at many Brisbane closed landfills may therefore not be warranted.

Recently, less-costly capping designs that incorporate leachate-tolerant plants have been investigated as an alternative capping system to engineered caps. These alternative designs involve planting trees, shrubs and grasses directly into the landfill cover material, or into a thin layer of topsoil (approximately $300 \mathrm{~mm}$ ) above the landfill cover, and have been termed phytoremediation caps (or phytocaps). The phytocap principally involves the use of plants that are tolerant to highly saline, ammonium-rich leachate, and is closely related to the established remediation technology referred to as phytoremediation (Brooks 1998). The plants perform a variety of tasks, which include creating a soil-water deficit through transpiration, encouraging soil microbial activity for removing (within the soil biomass) and converting leachate chemicals (e.g. organic nitrogen) into usable forms (inorganic nitrogen), acting as a sink for leachate contaminants through plant uptake, and improving soil structure within the capping system.

In 2002, Brisbane City Council (BCC) commenced a major innovative project to investigate the applicability of phytocapping as a method of managing leachate at a former major landfill. This represents one of the first phytoremediation trials to be undertaken at a Queensland landfill, and possibly the first of its kind in Australia (Phillips 2003). The principal aims of the trial were to:

- assess whether the concept of phytoremediation can be incorporated into landfill capping design;

- identify a range of native plants that have the potential to treat leachate on-site; and

- to evaluate the suitability of the phytocap as an alternative capping system to the more costly engineered cap.

The work reported in this paper identifies some of the major issues associated with selection of capping materials, and provides an overview of the cap performance in comparison with an engineered cap. The suitability of various plant species used in the trial to tolerate landfill leachate will be presented by Greenway et al. (2004).

\section{MATERIALS AND METHODS}

\section{Site description}

The field trial was undertaken at the former Nudgee Landfill site $\left(27^{\circ} 21.20^{\prime} \mathrm{S} 153^{\circ} 055^{\prime} \mathrm{E}\right)$, in Brisbane, Queensland, Australia. The landfill is underlain by 1.4$4.0 \mathrm{~m}$ of alluvial floodplain sediments (clay, silt and gravel), which in turn are underlain by extremely weathered basalt. Groundwater at the site is essentially tidal, and the dominant flow direction is to the north in response to the general surface drainage direction. The former Nudgee Landfill has a tipping history extending from September 1976 to January 1988 (136 months), and was used as a general refuse tip over this period. It is currently operating as a hard fill site, and an on-site transfer station has been in operation since 1993. The site covers an approximate area of $720000 \mathrm{~m}^{2}$, and extends to an approximate depth of $20 \mathrm{~m}$. Initial construction of the landfill did not include a liner system, and a significant proportion of the waste mass is in direct contact with the tidal groundwater (BCC, personal communication).

\section{Description of the field trial}

The trial comprised twelve plots ( $22.5 \mathrm{~m}$ long by $12 \mathrm{~m}$ wide), and included two capping designs (engineered and phytocap), three leachate qualities $(0,40$ and $100 \%$ ) and two replicates of each plot (replicates 1 and 2 ). The engineered cap comprised a compacted clay layer (about $500 \mathrm{~mm}$ thick) above the existing landfill cover, underlying a gravel drain layer (300 mm thick), underlain by sandy clay loam topsoil ( $300 \mathrm{~mm}$ thick). A geotextile layer was placed between the gravel and topsoil layers to minimise the movement of fine materials into the gravel matrix. Leachate was sourced directly from the landfill, and its general composition is presented in Table 1. Leachate was mixed with proportional amounts of reticulated water to obtain solution concentrations of $0 \%$ (control), $40 \%$ and $100 \%$ leachate strength.

Preliminary studies (Ashwath and Hood 2001) identified 18 plant species that were suitable for the trial, which included a number of trees (acacias, eucalypts and grevilleas) and grasses (Vetiva and Juncus). Species were planted in a randomised block design, and drip irrigated at a daily rate of $3.7 \mathrm{~mm}$ (approximately equivalent to 1.5 times the annual rainfall). Plant characteristics such as height and girth were monitored throughout the trial, and leaf samples of each plant were collected for total $\mathrm{N}$ and total $\mathrm{C}$ analysis using mass spectrometry. Soil from across each plot was analysed for gravimetric water content, $\mathrm{pH}, \mathrm{EC}$, and $2 \mathrm{M}$ $\mathrm{KCl} \mathrm{NH}{ }_{4}$ and $\mathrm{NO}_{3}$, using standard techniques. 
Table 1. Composition of leachate from the Nudgee Landfill (all units in $\mathrm{mg} / \mathrm{L}$ unless otherwise stated)

\begin{tabular}{|l|c|}
\hline Parameter & Value \\
\hline $\mathrm{EC}(\mu \mathrm{S} / \mathrm{cm})$ & 15000 \\
$\mathrm{pH}$ & 7.1 \\
Total organic carbon (TOC) & 230 \\
$\mathrm{BOD}_{5}$ & 21 \\
$\mathrm{Total}_{\mathrm{K}} \mathrm{Kjeldahl} \mathrm{nitrogen} \mathrm{(TKN)}$ & 510 \\
$\mathrm{NH}_{4}-\mathrm{N}$ & 330 \\
$\mathrm{NO}_{3}-\mathrm{N}$ & 4.9 \\
$\mathrm{Total}_{\text {alkalinity }\left(\mathrm{CaCO}_{3} \text { equivalent }\right)}$ & 1700 \\
$\mathrm{SO}_{4}$ & 240 \\
$\mathrm{Cl}$ & 5000 \\
$\mathrm{Ca}$ & 130 \\
$\mathrm{Mg}$ & 180 \\
$\mathrm{Na}$ & 2900 \\
\hline
\end{tabular}

Table 2. Relevant physical and chemical properties of the sandy clay loam topsoil

\begin{tabular}{|l|c|}
\hline Parameter & Topsoil \\
\hline Texture & Sandy clay loam \\
Stones $>20 \mathrm{~mm}$ & $2-3 \%$ \\
Large particles $>2 \mathrm{~mm}$ & $10 \%$ \\
$\mathrm{pH}$ & 7.5 \\
$\mathrm{EC}(\mu \mathrm{S} / \mathrm{cm})$ & 260 \\
Organic carbon $(\%)$ & 1.22 \\
Oxalate-Fe $(\%)$ & 0.38 \\
Oxalate-Al $(\%)$ & 0.13 \\
$\mathrm{Cl}(\mathrm{mg} / \mathrm{kg})$ & 273 \\
$\mathrm{NO}{ }_{3}(\mathrm{mg} / \mathrm{kg})$ & 1.5 \\
$\mathrm{P}(\mathrm{mg} / \mathrm{kg})$ & 99 \\
$\mathrm{SO}{ }_{4}(\mathrm{mg} / \mathrm{kg})$ & 33 \\
$\mathrm{Ca}(\mathrm{cmol} / \mathrm{kg})$ & 4.42 \\
$\mathrm{Mg}(\mathrm{cmol} / \mathrm{kg})$ & 2.93 \\
$\mathrm{~K}(\mathrm{cmol} / \mathrm{kg})$ & 0.66 \\
$\mathrm{Na}(\mathrm{cmol} / \mathrm{kg})$ & 1.16 \\
$\mathrm{Cu}(\mathrm{mg} / \mathrm{kg})$ & 3 \\
$\mathrm{Zn}(\mathrm{mg} / \mathrm{kg})$ & 3.58 \\
Coarse sand $(\%)$ & 39 \\
Fine sand $(\%)$ & 40 \\
$\mathrm{Silt}(\%)$ & 6 \\
Clay $(\%)$ & 15 \\
\hline
\end{tabular}

\section{Hydraulic conductivity and aggregate stability}

Soil used in construction of the surface layer (a sandy clay loam) was studied because this material was in direct contact with the leachate. Relevant initial properties of this soil are presented in Table 2.

The soil's saturated hydraulic conductivity $\left(k_{\text {sat }}\right)$ was determined using tapwater (sodium adsorption ratio $(\mathrm{SAR})=1), 40 \%$ leachate $(\mathrm{SAR}=12)$ and $100 \%$ leachate $(\mathrm{SAR}=27)$ to reflect treatments used in the field trial. Approximately 150 grams of soil were packed into a glass burette, and a constant depth of solution of about $5 \mathrm{~cm}$ was maintained above the soil surface. The soil was sequentially leached as stated in Table 3. Solution was continuously added to each soil column until the discharge rate (i.e. volume of outflow per unit time) remained constant for three successive readings. Alternating the solutions between leachate and tapwater simulated conditions expected in the field experiment where leachate-affected soil will be intermittently leached with low ionic strength rainwater. The $0.1 \mathrm{M} \mathrm{CaCl}_{2}$ solution was used to determine if any loss of $k_{\mathrm{sat}}$ due to leachate and/or tapwater could be recovered using a concentrated solution containing a multivalent cation. The $k_{\text {sat }}$ was calculated as:

$$
q=(V \div A t)=-k_{\text {sat }} \times \mathrm{d} H / \mathrm{d} z
$$

where

$$
\begin{aligned}
q= & \text { the Darcian flux density }\left(\mathrm{m}^{3} / \mathrm{m}^{2} . \mathrm{s}\right) \\
V= & \text { volume of drainage }\left(\mathrm{m}^{3}\right) ; \\
A \quad= & \text { cross-sectional area available for flow } \\
& \left(\mathrm{m}^{2}\right) ; \\
t= & \text { time }(\mathrm{s}) ; \\
k_{\mathrm{sat}}= & \text { saturated hydraulic conductivity }(\mathrm{m} / \mathrm{s}) ; \\
H \quad= & \text { hydraulic head }(\mathrm{m}) ; \\
z \quad= & \text { distance }(\mathrm{m}) ; \text { and }
\end{aligned}
$$

$\mathrm{d} H / \mathrm{d} z=$ the hydraulic gradient $(\mathrm{m} / \mathrm{m})$; the negative sign indicates water flows in the direction of decreasing $H$.

Aggregate stability testing was conducted $(n=2)$ using undisturbed samples of sandy clay loam topsoil material from the field trial. Aggregates were immersed in solutions of deionised water, tapwater, $40 \%$ leachate and $100 \%$ leachate, and the extent of slaking and dispersion was evaluated visually. Individual jars $(8 \times 250 \mathrm{~mL})$ were filled with solution to attain a ponded depth of $5 \mathrm{~cm}$. A soil aggregate approximately $1 \mathrm{~cm}$ in diameter was then carefully placed in the solution. The aggregate was visually observed for ten minutes, and the effects of solution type on aggregate stability were recorded. The aggregate was left undisturbed in the jar for 20 hours, after which its condition was recorded. Observations of the effect of solution on aggregate stability involved the presence of air escaping from the aggregate seen as bubbles in the solution, slumping of the aggregate, and clarity or cloudiness of the solution from dispersed fine material. 
Table 3. Leaching sequence to assess solution type on $\boldsymbol{k}_{\text {sat }}$

\begin{tabular}{|c|rllllll|}
\hline Sequence & \multicolumn{7}{|c|}{ Sequence of solutions added } \\
\hline 1 & Tapwater & $\rightarrow$ & Tapwater & $\rightarrow$ & Tapwater & $\rightarrow$ & $0.1 \mathrm{M} \mathrm{CaCl}_{2}$ \\
2 & $40 \%$ Leachate & $\rightarrow$ & Tapwater & $\rightarrow$ & $40 \%$ Leachate & $\rightarrow$ & $0.1 \mathrm{M} \mathrm{CaCl}_{2}$ \\
3 & $100 \%$ Leachate & $\rightarrow$ & Tapwater & $\rightarrow$ & $100 \%$ Leachate & $\rightarrow$ & $0.1 \mathrm{M} \mathrm{CaCl}_{2}$ \\
\hline
\end{tabular}

\section{Sorption isotherms and transformation}

Sorption isotherms $(n=2)$ were determined for the sandy clay loam topsoil using the standard batch technique. Leachate was diluted with deionised water to obtain eight (8) initial solutions, and these solutions represented $0,5,10,20,40,60,80$ and $100 \%$ leachate. The range of total dissolved $\mathrm{N}(\mathrm{TN}), \mathrm{NH}_{4}-\mathrm{N}$, total dissolved carbon (TC), total dissolved organic carbon (TOC) of these solutions were: 0-500, 0-430, 0-600, and $0-380 \mathrm{mg} / \mathrm{L}$, respectively. Soil (5 $\mathrm{g}$ on an equivalent air-dry basis) was weighed into a series of $50 \mathrm{ml}$ polypropylene centrifuge tubes, and $25 \mathrm{~mL}$ of solution added. The suspension was shaken end-over-end for two hours, then centrifuged at $3000 \mathrm{rpm}$ for $30 \mathrm{~min}-$ utes, and passed through a $0.45 \mu \mathrm{m}$ filter prior to analysis. The initial and final solutions were analysed for $\mathrm{NH}_{4}$ (flow injection analysis techniques (FIA)), and total N, TC and TOC (Shimadzu Total Carbon and Nitrogen Analyser). The difference between total $\mathrm{N}$ and $\mathrm{NH}_{4}$ concentrations was assumed to represent the total dissolved organic N (TON) fraction. Ammonium, TON and TOC adsorption data were fitted to the Freundlich equation:

$$
S=k_{\mathrm{f}} c^{n}
$$

where

$S=$ the increase in sorbed $\mathrm{NH}_{4}$ (TON or TOC) per unit weight of soil $(\mathrm{mg} / \mathrm{kg})$;

$c=$ the final $\mathrm{NH}_{4}$ (TON or TOC) solution concentration $(\mathrm{mg} / \mathrm{L})$;

$k_{\mathrm{f}}$ and $n$ are empirical fitting constants

Nitrogen transformations in the sandy clay loam topsoil were investigated using deionised water, tap- water, $40 \%$ leachate and $100 \%$ leachate. Approximately $15 \mathrm{~g}$ of soil (air-dry, $<2 \mathrm{~mm}$ ) were placed into individual $20 \mathrm{~mL}$ polypropylene syringe barrels (Chux cloth and GF/A filter paper in base of syringe; Chux cloth on soil surface) and leached with approximately $15 \mathrm{~mL}$ of one of the above solutions. The syringe barrels were covered with perforated plastic film, and placed in a vertical position. A sample of the soil solution was extracted after $0,1,3,7$ and 14 days by highspeed centrifugation $\left(10000 \mathrm{rpm}\right.$ for 1 hour at $\left.4^{\circ} \mathrm{C}\right)$ using the procedure by Elkhatib et al. (1987). The extracted solutions were analysed for $\mathrm{NH}_{4}$ and $\mathrm{NO}_{3}$ (FIA), and total N, TC and TOC (Shimadzu Total Carbon and Nitrogen Analyser). The production of $\mathrm{NO}_{3}$ was modelled using the average $(n=2) \mathrm{NH}_{4}$ and $\mathrm{NO}_{3}$ data, using:

$$
c_{\mathrm{NO} 3}=a \times t^{b 1} \times c_{\mathrm{NH} 4}{ }^{b 2}
$$

where

$$
\begin{aligned}
c_{\mathrm{NO} 3}= & \text { concentration of } \mathrm{NO}_{3} \text { in the extracted solu- } \\
& \text { tion }(\mathrm{mg} / \mathrm{L}) \\
c_{\mathrm{NH} 4}= & \text { concentration of } \mathrm{NH}_{4} \text { in the extracted solu- } \\
& \text { tion }(\mathrm{mg} / \mathrm{L})
\end{aligned}
$$

$t$ is time (days); and

$a, b 1$ and $b 2$ are constants.

Equation (3) allows the effects of time and solution $\mathrm{NH}_{4}$ concentrations to be included in $\mathrm{NO}_{3}$ production, and has been successfully used to model $\mathrm{P}$ kinetics in soils (Gerritse 1993).
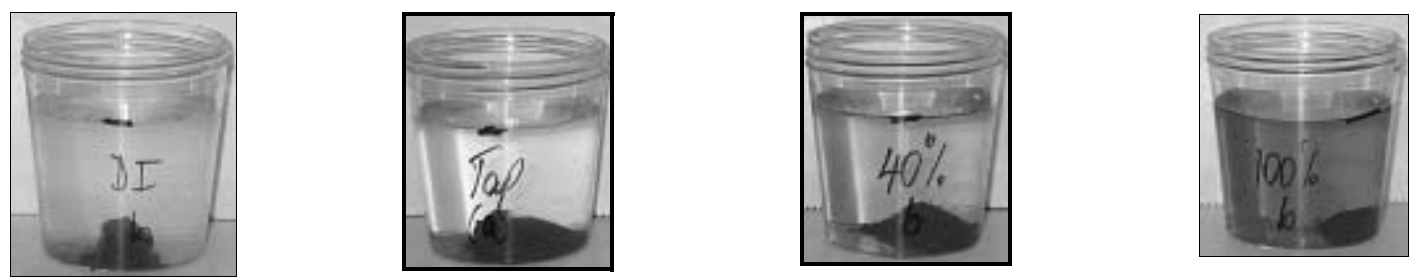

FIGURE 1. EFFECT OF SOLUTION TYPE ON AGGREGATE STABILITY FOR THE SANDY CLAY LOAM TOPSOIL 
(a)

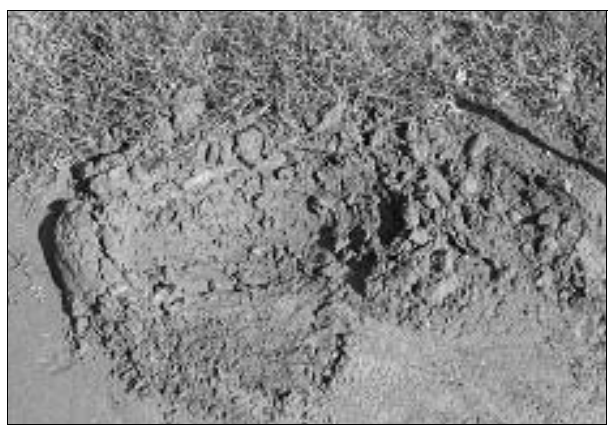

(b)

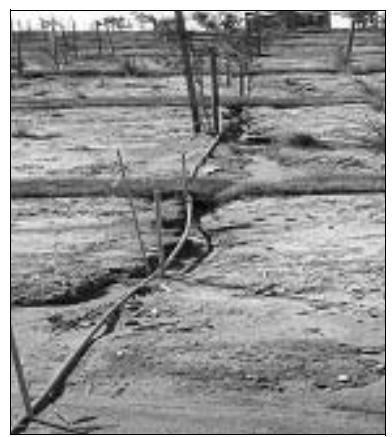

FIGURE 2. DETERIORATION IN PHYSICAL PROPERTIES OF THE FIELD PLOTS DURING EARLY STAGES OF THE TRIAL, DUE TO (A) SEDIMENT TRANSPORT, AND (B) EROSION

\section{RESULTS AND DISCUSSION}

\section{Aggregate stability}

All aggregates slumped immediately on immersion in the various solutions (Figure 1). Air was observed to diffuse out of the aggregate into the solution, which brought about disintegration of the aggregate. Slumping can be qualitatively assessed based on a score of 0 to 4 , where 0 represents no slumping, 1 represents slumping largely around the aggregate edges, 2 represents aggregate collapse into angular pieces, 3 represents aggregate collapse into small ( $<2 \mathrm{~mm}$ diameter) rounded pieces, forming a cone shape, and 4 represents aggregate collapse into single grains. A score of 3 best described the aggregate stability for the sandy clay loam topsoil (Figure 1), and is consistent with the deterioration in soil physical properties observed in the field trial (Figure 2). The tendency of the topsoil to slump on immersion can be attributed to its lack of binding materials such as organic matter and sesquioxides (Table 2).

Dispersion was only observed in the deionised water treatment (Figure 1(a)), and recorded a dispersion index (on a rating between 0 to 4 ) of about 2 (i.e. 'moderate dispersion with obvious milkiness'). The absence of this effect in the other treatments may be attributed to the higher ionic strength of the tapwater and leachate solutions, which can reduce dispersion through compression of the diffuse double layer. When $>6 \%$ of the cation exchange capacity of a soil is occu-

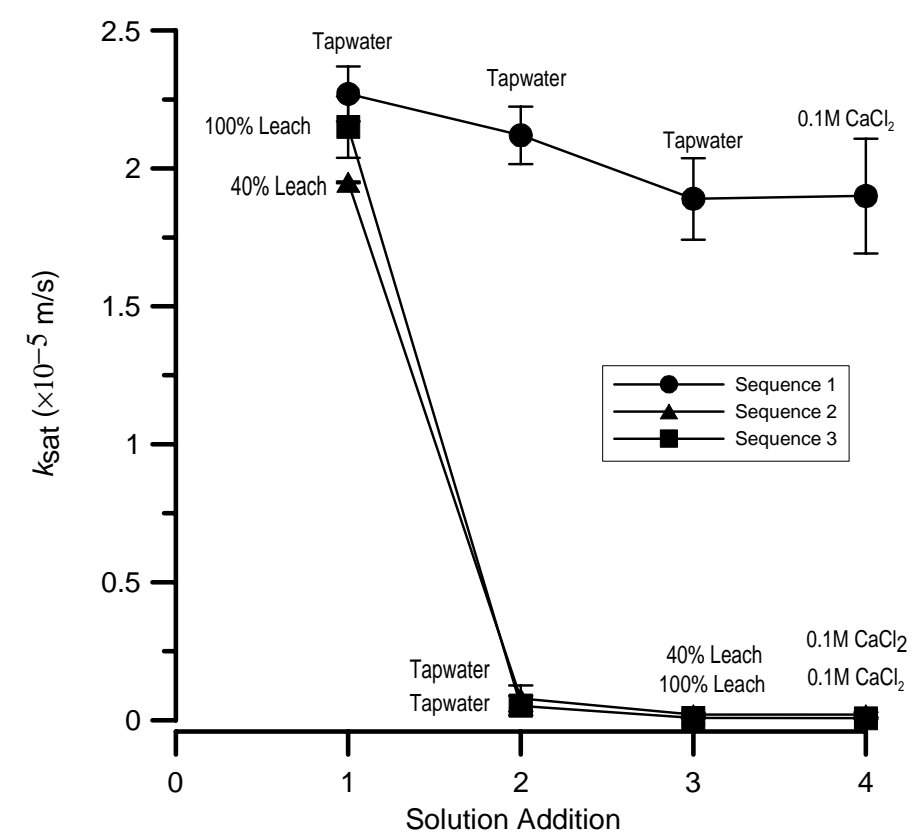

FIGURE 3. EFFECT OF LEACHING SOLUTION ON $K_{\text {SAT }}$ FOR THE SANDY CLAY LOAM TOPSOIL 

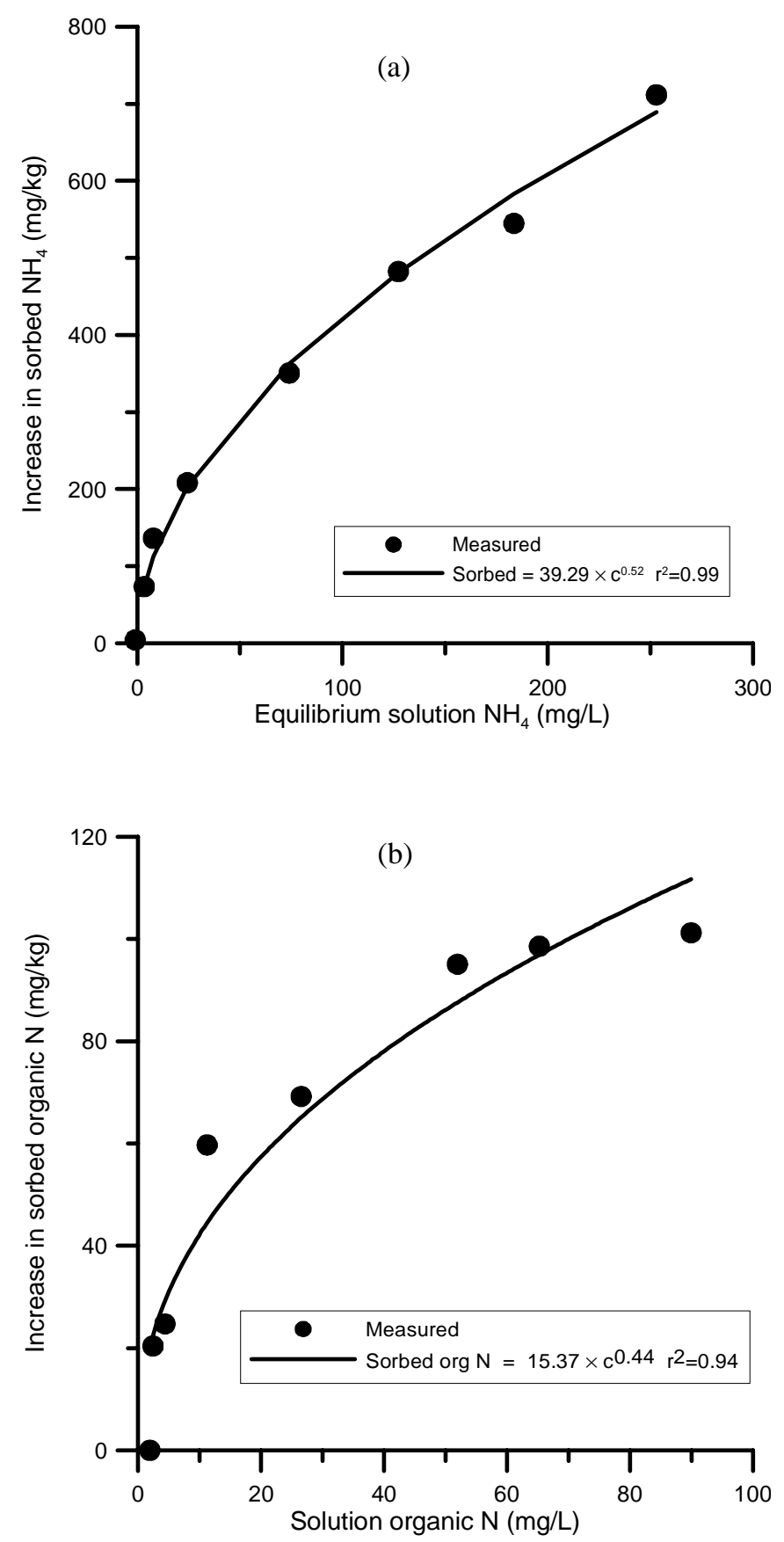

FIGURE 4. (A) AMMONIUM $\left(\mathrm{NH}_{4}\right)$ AND (B) ORGANIC N SORPTION ISOTHERMS FOR THE SANDY CLAY LOAM TOPSOIL

pied by sodium $(\mathrm{Na})$, soils are regarded as sodic. On wetting, the $\mathrm{Na}$ cannot bind the clay particles together, and since $\mathrm{Na}$ cannot overcome the repulsive forces, clay dispersion occurs. However, increases in solution concentration can overcome this repulsion, thereby causing reducing dispersion. The topsoil at the Nudgee trial had an exchangeable sodium percentage (ESP) of
$12 \%$, hence it was sodic. Re-wetting with deionised water $(\mathrm{EC}=1.3 \mu \mathrm{S} / \mathrm{cm})$ would encourage dispersion, as observed in Figure 1. However, the concentration of tapwater $(\mathrm{EC}=394 \mu \mathrm{S} / \mathrm{cm}$; which most likely also contained the divalent cations $\mathrm{Ca}$ and $\mathrm{Mg}$ ), and leachate $\left(\mathrm{EC}_{40 \%}=8030 \mu \mathrm{S} / \mathrm{cm}\right.$ and $\left.\mathrm{EC}_{100 \%}=18200 \mu \mathrm{S} / \mathrm{cm}\right)$ 


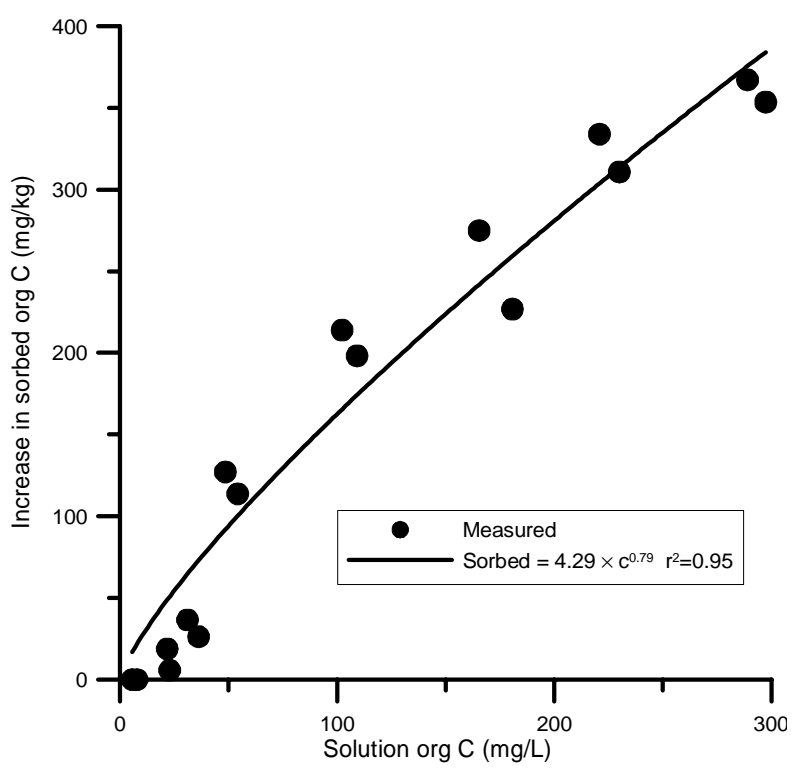

FIGURE 5. ORGANIC CARBON SORPTION ISOTHERM FOR THE SANDY CLAY LOAM TOPSOIL

appeared to be sufficiently high to overcome the repulsive forces, thereby avoiding clay dispersion.

\section{Effect of leachate on saturated hydraulic conductivity $\left(\boldsymbol{k}_{\text {sat }}\right)$}

The effect of leaching solution on $k_{\text {sat }}$ for each soil material is presented in Figure 3. Initially, $k_{\text {sat }}$ was about $2 \times 10^{-5} \mathrm{~m} / \mathrm{s}$, irrespective of leaching solution (Figure 3). Subsequent leaching with tapwater reduced $k_{\text {sat }}$, particularly for those soils initially leached with leachate. For these treatments, tapwater reduced $k_{\text {sat }}$ to about $1 \times 10^{-6} \mathrm{~m} / \mathrm{s}$, and subsequent addition of leachate or $0.1 \mathrm{M} \mathrm{CaCl}_{2}$ failed to increase $k_{\text {sat }}$ to its initial value. This suggests that the detrimental effects of sequential application of leachate and tapwater on the hydraulic properties of this sandy clay loam soil were irreversible (Scotter 1985).

The reductions in $k_{\text {sat }}$ may be a result of mechanisms such as slumping, swelling pressures, and/or clay dispersion. Of these mechanisms, swelling pressures and dispersion were considered to be of minor importance. Firstly, the soil contained a relatively low clay percentage (Table 2), and, although not quantified, the clay mineralogy is unlikely to contain highly reactive materials such as smectite. Secondly, earlier data showed that little dispersion of the clay-sized material occurred in the presence of tapwater and leachate (Figure 1). Thus, it was concluded that slumping represented the dominant mechanism for the deterioration in aggregate stability.

During the $k_{\text {sat }}$ experiments, it was observed that the surface few millimetres of the soil columns contained a high proportion of very fine soil material (probably generated through slumping), and this material may have formed a low-permeability layer that inhibited infiltration of applied solutions. The finding that both the leachate and the $0.1 \mathrm{M} \mathrm{CaCl}_{2}$ could not reflocculate this material, suggests that the formation of a lowpermeability layer was an irreversible process. Therefore, blockage of conducting pores by a layer of colloidal material after slaking (particularly at the soil surface) may be the most likely cause for the large, permanent decrease in $k_{\text {sat }}$ observed in these soils. A similar finding was reported by Minhas and Sharma (1986) for a clay loam soil.

\section{Nitrogen and carbon adsorption isotherms}

The sorption isotherms clearly show that the topsoil has a good ability to remove leachate $\mathrm{NH}_{4}$ (Figure 4a). Cation exchange was considered to be the primary removal mechanism, with leachate $\mathrm{NH}_{4}$ undergoing exchange with resident exchangeable $\mathrm{Ca}, \mathrm{Mg}$ and $\mathrm{Na}$ (Table 2). The data were very well described by the Freundlich Equation, with correlation coefficients of around 0.99 (Figure 4a).

The data also showed that the topsoil removed significant amounts of organic $\mathrm{N}$, and that the maximum increase in adsorbed concentration was about $100 \mathrm{mg} /$ $\mathrm{kg}$ (Figure 4b). Organic compounds which contain N (e.g. amino acids, polypeptides, and proteins) can be sorbed by various processes, such as: hydrophobic sorption, hydrogen bonding, ligand exchange, cation exchange and anion exchange (Thurman 1985; Tisdale et al. 1993). The short duration of the isotherm study, 
(a)

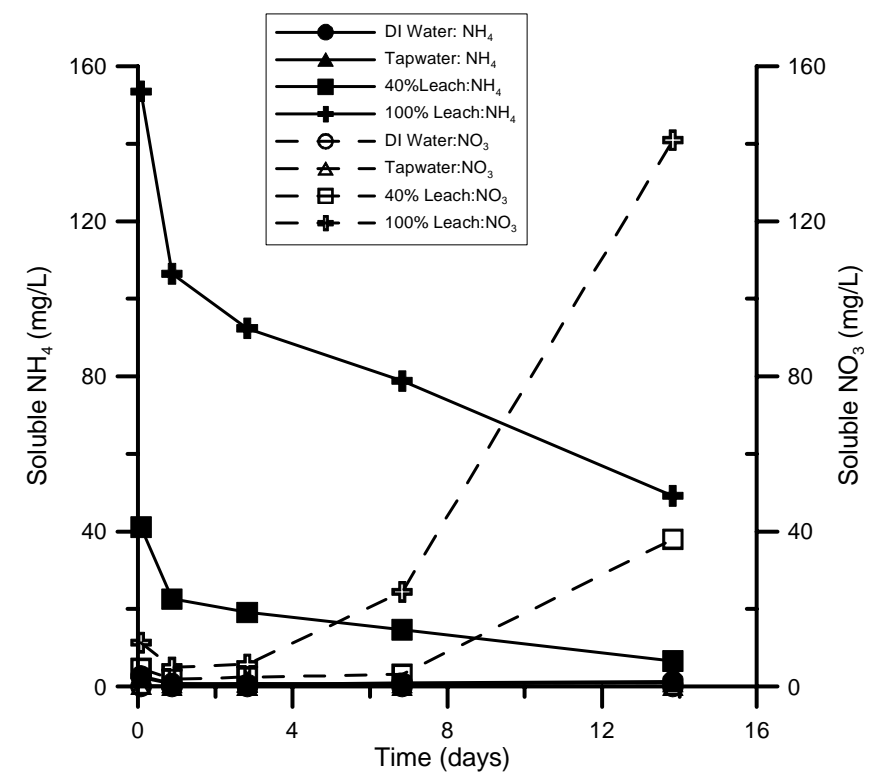

(b)

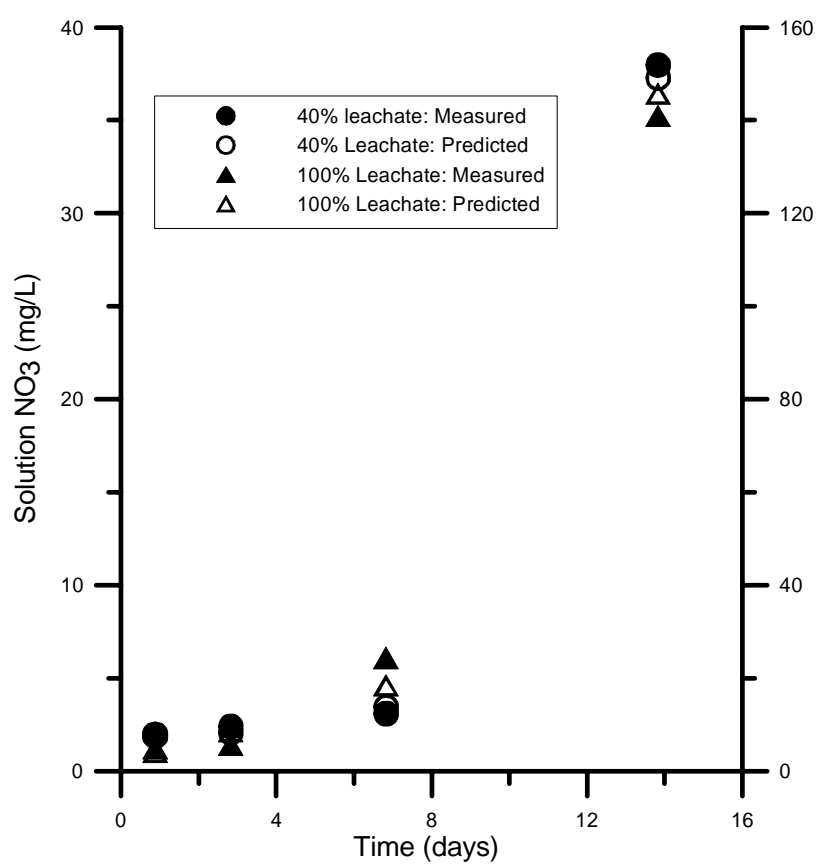

गे
है
O̊
$\frac{1}{c}$
을
흥
क

FIGURE 6. (A) EFFECTS OF TIME AND SOLUTION TYPE ON WATER-SOLUBLE NH AND NO$_{3}$ CONCENTRATIONS IN THE SANDY CLAY LOAM TOPSOIL, AND (B) PREDICTED SOLUBLE NO${ }_{3}$ CONCENTRATIONS

coupled with no obvious increases in inorganic $\mathrm{N}$, suggests that the loss of organic $\mathrm{N}$ did not result from microbial activity. It is possible that this loss was due to reactions with the soil charged-components (i.e. clay minerals, organic matter, and/or Fe oxides) since decreases in soluble organic carbon were also found to occur (Figure 5).
Kaiser and Zech (2000) and Kaiser (2001) studied the sorption of dissolved organic carbon, nitrogen, phosphorus and sulphur by a range of soil materials. These workers found that dissolved organic $\mathrm{N}$ sorbed to amorphous $\mathrm{Fe}$ and $\mathrm{Al}$ hydrous oxides almost completely, and that no sorption maxima were reached. Sorption by clay minerals such as kaolinite and illite, however, was found to be non-linear, and a maximum 
sorption value was observed. This type of isotherm was also observed for the topsoil (Figure 4b). This trend was not observed for dissolved organic carbon (Figure 5). This is consistent with the observations of other workers (Kaiser and Zech 2000) who found sorptive retention of organic $\mathrm{N}$ to be less than that of organic $\mathrm{C}$. This relationship is also supported by the smaller value of $n$ in the Freundlich equation for organic $\mathrm{N}(n=0.44)$ relative to that for organic $\mathrm{C}(n=0.79)$. Reduced sorption of organic $\mathrm{N}$ relative to organic $\mathrm{C}$ has been attributed to much of the $\mathrm{N}$-containing compounds being present in the weakly sorbed hydrophilic fraction of dissolved organic matter (Jones and Hodge 1999; Kaiser and Zech 2000).

\section{Nitrogen transformations}

Solution $\mathrm{NH}_{4}$ concentrations decreased as a function of time in all treatments, but these effects were most pronounced in the $40 \%$ and $100 \%$ leachate solutions (Figure 6a). During the early time period ( $<1$ day), the reduction in solution $\mathrm{NH}_{4}$ levels can be largely attributed to cation exchange with resident cations, as evidenced by the adsorption isotherms (Figure 4a).

Solution $\mathrm{NH}_{4}$ concentrations continued to decline throughout the 14-day study (Figure 6a). Ammonium sorption is commonly regarded as instantaneous, so mechanisms additional to cation exchange were contributing to the loss of solution $\mathrm{NH}_{4}$. Figure 6 a clearly shows that solution $\mathrm{NO}_{3}-\mathrm{N}$ concentrations steadily increased between day 3 and day 14, particularly during the later stages of the experiment. It is well known that, under appropriate conditions, solution $\mathrm{NH}_{4}$ is readily transformed to $\mathrm{NO}_{3}-\mathrm{N}$ (Tisdale et al. 1993). The lag-time of about two days between $\mathrm{NH}_{4}$ addition and $\mathrm{NO}_{3}$ production can most likely be attributed to the time required for establishment and growth of the nitrifying population (Tisdale et al. 1993).

The nitrification rate for soil treated with $40 \%$ leachate varied between 0.5 and $2.4 \mathrm{mg} / \mathrm{kg} / \mathrm{day}$, and between 1.2 and $8.5 \mathrm{mg} / \mathrm{kg} / \mathrm{day}$ for the $100 \%$ leachate treatment. These rates were consistent with those reported in the literature (Tisdale et al. 1993; Phillips 2002a). This suggests that nitrification was a major cause for the decline in solution $\mathrm{NH}_{4}$, and that during prolonged incubation (i.e. between irrigation events), a significant proportion of solution $\mathrm{NH}_{4}$ not retained by the soil exchange sites could be transformed to $\mathrm{NO}_{3}$, and subsequently lost through leaching back into the strong reducing $(\mathrm{Eh}<-100 \mathrm{mV})$ environment of the landfill and/or plant uptake (Phillips 2002b).

The rate of $\mathrm{NO}_{3}$ production (Figure 6b) was simulated very well by Equation (3), and values for the parameters $a, b 1$ and $b 2$ for the $40 \%$ and $100 \%$ leachate treatments are presented in Table 4 . Since $\mathrm{N}$ dynamics are not typically described using this relationship, the values of the parameters cannot be compared with published literature; however, it would be relatively straightforward to incorporate this equation into existing solute transport models to describe soil $\mathrm{N}$ coupled leaching-transformation behaviour in the design of capping systems.

Table 4. Values of the parameters obtained by fitting Equation (3) to the $\mathrm{NO}_{3}$ production data, and associated correlation coefficient $\left(r^{2}\right)$

\begin{tabular}{c|cccc}
\hline Solution & $\boldsymbol{a}$ & $\boldsymbol{b 1}$ & $\boldsymbol{b 2}$ & $\boldsymbol{r}^{\mathbf{2}}$ \\
\hline $40 \%$ & 4.82 & -0.44 & -3.36 & 0.98 \\
$100 \%$ & 9.19 & 0.19 & -4.23 & 0.90 \\
\hline
\end{tabular}

\section{IMPLICATIONS FOR CAPPING DESIGN}

The physical, chemical and biological properties of soil materials used in the construction of capping systems need to be fully understood before appropriate selection of materials can be made. In situations where infiltration is to be minimised, clay soils that exhibit a very low permeability and a resistance to desiccation would be the favoured material. However, for phytocaps in which infiltration of surface-applied leachate is required, a soil material that can maintain an open network of pores would be the preferred choice. Importantly, the porous structure of the final design must maintain pore connectivity between the cap surface and the bulk soil matrix, because, if infiltration rates are adversely affected through slumping, dispersion, and/ or compaction, then the system will fail. In the field trial reported here, failure of the capping system resulted in limited infiltration of applied leachate, and considerable erosion of the cap surface. Remediation strategies have, however, been put in place to rectify this problem at the Nudgee Landfill, and involved spreading a 50-75 mm depth of mulch across the surface of the topsoil. This has been observed to reduce runoff velocities, and hence erodability, and to encourage a more even spreading of the applied leachate across the plot.

The topsoil did have good chemical and biological properties, as expressed in its ability to sorb added $\mathrm{NH}_{4}$, organic $\mathrm{N}$ and organic $\mathrm{C}$. These properties play an integral role in removing leachate contaminants from the solution phase, thereby reducing environmental impacts, and in transforming contaminants into forms favourable for plant uptake.

The findings from this study have provided excellent baseline information for developing appropriate designs for phytocap systems, and have emphasised the 
importance of correct selection of materials for use in their construction.

\section{ACKNOWLEDGEMENTS}

We wish to thank Brisbane City Council for funding support and for making a field site available for undertaking this project. We also acknowledge the work of Dr Nanjappa Aswhath from Central Queensland University, and Mr Richard Yeates from Phytolink Australia, during the early stages of the trial.

\section{REFERENCES}

Ashwath, N. and Hood, B. (2001) Screening of 70 Tree and Shrub Species for Tolerance to Landfill Leachate. Primary Industries Research Centre, Central Queensland University, Rockhampton, Qld, Australia

Brooks, R.R. (1998) Plants that Hyperaccumulate Heavy Metals. CAB International, New York

Elkhatib, E.A., Hern, J.L. and Staley, T.E. (1987) A rapid centrifugation method for obtaining soil solution. Soil Science Society of America Journal, 51, 578-583

Gerritse, R.G. (1993) Mobility of phosphate from wastewater in calcareous sands of Rottnest Island (W.A.). Australian Journal of Soil Research, 31, 235-244

Greenway, M., Phillips, I.R. and Robertson, S. (2004) Use of phytocaps in remediation of closed landfills - role of plants on leachate control and design. In preparation

Henken-Mellies, U. and Gartung, E. (2004) Long-term observation of alternative landfill capping systems - field tests on a landfill in Bavaria. Land Contamination \& Reclamation, 12, 21-28.

Jones, D.L. and Hodge, A. (1999) Biodegradation kinetics and sorption reactions of three differently charged amino acids in soil and their effects on plant organic nitrogen availability. Soil Biology and Biochemistry, 31, 1331-1342
Kaiser, K. (2001) Dissolved organic phosphorus and sulphur as influenced by sorptive interactions with mineral subsoil horizons. European Journal of Soil Science, 52, 489-493

Kaiser, K. and Zech, W. (2000) Sorption of dissolved organic nitrogen by acid subsoil horizons and individual mineral phases. European Journal of Soil Science, 51, 403411

Minhas, P.S. and Sharma, D.R. (1986) Hydraulic conductivity and clay dispersion as affected by application sequence of saline and simulated rain water. Irrigation Science, 7, 159167

Phillips, I.R. (2002a) Phosphorus sorption and nitrogen transformations in soils treated with piggery wastewater. Australian Journal of Soil Research, 40, 335-349

Phillips, I.R. (2002b) Nutrient leaching in large undisturbed soil cores following surface applications of piggery wastewater. Australian Journal of Soil Research, 40, 515-532

Phillips, I.R. (2003) Using Phytoremediation in the Management of Closed Landfills: Effects of Leachate on Soil Hydraulic Properties and Nitrogen Uptake by Plants. Unpublished Report prepared for Brisbane City Council, November, Brisbane, Australia

Scotter, D.R. (1985) The effect of electrolyte solutions on the unsaturated hydraulic conductivity of a sodic clay soil. Australian Journal of Soil Research, 23, 301-307

Smith, J.W.N., Boshoff, G. and Bone, B.D. (2003) Good practice guidance on permeable reactive barriers for remediating polluted groundwater, and a review of their use in the UK. Land Contamination \& Reclamation, 11, 411-418

Thorley, C.B. and Boczek, E. (2001) Design and monitoring of landfill cover systems. 2nd Australia-New Zealand Conference on Environmental Geomechanics, November, Newcastle, Australia

Thurman, E.M. (1985) Organic Chemistry of Natural Waters. Martinus Nijhoff / Dr W. Junk Publishers, Boston, USA, 497 pp

Tisdale, S.L., Nelson, W.L., Beaton, J.D. and Havlin, J.L. (1993) Soil Fertility and Fertilizers. 5th edition, Macmillan Publishing Company, New York, USA 